\title{
Uretroplastia de substituição com segmentos tubulares autólogos de mucosa bucal em cães ${ }^{1}$
}

\author{
Neusa Margarida Paulo ${ }^{2}$ \\ Adriana Braga Siqueira Rôlla ${ }^{3}$ \\ Simone Moraes Porto ${ }^{4}$ \\ Luciano Schneider da Silva ${ }^{5}$ \\ George Alves de Brito ${ }^{6}$ \\ José de Sousa Freitas ${ }^{7}$
}

Paulo NM, Rôlla ABS, Porto SM, Silva LS, Brito GA, Freitas JS. Uretroplastia de substituição com segmentos tubulares autólogos de mucosa bucal em cães. Acta Cir Bras [serial online] 2003 JulAgo;18(4). Disponível em URL: http://www.scielo.br/acb.

RESUMO - Objetivo: Avaliar a reconstrução de defeitos experimentais na uretra do cão com a implantação de segmentos tubulares de mucosa bucal autóloga. Métodos: Procedeu-se à ressecção de cerca de $2 \mathrm{~cm}$ da uretra peniana de 20 cães. O defeito produzido foi corrigido por meio da anastomose de fragmento tubular de mucosa bucal autóloga, seccionado do lábio inferior. Resultados: Entre os animais operados, 14 (70\%) apresentaram jato urinário normal e seis (30\%) evidenciaram estenose confirmada por meio de exame radiológico realizado aos 60 dias do pósoperatório. Durante a necrópsia verificou-se a integridade dos implantes no sulco uretral, associado a infiltrado inflamatório de neutrófilos, linfócitos piócitos e histiócitos. As análises histológicas revelaram que os fragmentos implantados estavam recobertos pelo epitélio uretral. Conclusão: A implantação de segmentos autólogos de mucosa bucal é adequada para a reconstrução de defeitos uretrais iatrogênicos no cão, embora possa resultar em estenose pós-operatória.

DESCRITORES - Uretra. Enxerto autólogo. Mucosa bucal.

Introdução

Ao longo de décadas têm-se avaliado inúmeras técnicas reconstrutivas da uretra, principalmente do homem, com resultados variáveis no que se refere ao desencadeamento de problemas pós-operatórios como fistulas e estenose ${ }^{1,}$ 2,3,4. Embora as referências à reconstrução uretral na espécie canina sejam escassas pode-se salientar o trabalho de Iizuca e col..$^{5}$ os quais promoveram estudo experimental em cadelas, substituindo a mucosa uretral por tubo de mucosa lingual e o de El-Sherbiny e col. ${ }^{6}$ que avaliaram o tratamento de defeitos iatrogênicos na uretra perineal no cão por meio do implantes de pele, mucosa bucal e mucosa vesical. As terminações dos implantes tubulares foi espatulada e os resultados obtidos apontaram para a melhor qualidade dos implantes de mucosa bucal, sobretudo quando estes eram

1. Trabalho realizado no setor de cirurgia experimental da Escola de Veterinária da UFG. Goiânia - GO.

2. Professora Adjunta, Doutora. Disciplina de Cirurgia da Escola de Veterinária da UFG.

3. Acadêmica do curso de Medicina Veterinária da Escola de Veterinária da UFG.

4. Acadêmica do curso de Medicina Veterinária da Escola de Veterinária da UFG.

5. Acadêmico do programa de Mestrado da Escola de Veterinária da UFG.

6. Médico residente em urologia. Santa Casa de Misericórdia de Goiânia.

7. Professor Assistente de Radiologia da Escola de Veterinária da UFG. 
utilizados em retalho. Com relação ao desenvolvimento de estenoses, os autores reportaram que houve oito casos, correspondendo a $60 \%$, no grupo submetido aos enxertos tubulares com os três tipos de material e dentre estes, apenas um com a mucosa bucal, correspondendo a $25 \%$ dos animais avaliados.

A uretra do cão pode sofrer processos obstrutivos intraluminais e extraluminais. Dentre os primeiros pode-se citar as estenoses uretrais congênitas ou adquiridas, urólitos, neoplasias, uretrite infiltrativa granulomatosa, dentre outros. Enquadra-se no segundo grupo neoplasias, fraturas do osso peniano, mordidas e acidentes balísticos. Os defeitos anatômicos podem predispor o paciente às infecções do trato urinário ao interferir com a micção normal. Tais defeitos poderiam ainda permitir a migração ascendente de bactérias ${ }^{7}$.

As técnicas de uretroplastia no homem são indicadas quando o segmento uretral a ser extirpado é suficientemente longo, impedindo a anastomose término-terminal ${ }^{8}$. Nestes casos, ou na presença de hipospadia, a alternativa mais adequada é a substituição do tecido uretral por próteses tanto biológicas quanto sintéticas, tendo estas últimas sido revisadas por Da Silva ${ }^{9}$ Entre as biológicas pode-se citar pele de origem genital ou extragenital ${ }^{10}$, matriz acelular de colágeno ${ }^{11}$ e mucosa bucal ou vesical ${ }^{12,13,14,15,16}$.

Abordando os fatores que podem favorecer a uretroplastia com mucosa bucal, Pansadoro e col. ${ }^{14}$ salientaram que a ampla remoção do tecido submucoso torna o implante o mais fino possível, o que para Greenwell $e$ col. ${ }^{13}$ pode prevenir a má coaptação das bordas e conseqüentemente a formação de estenose. El-Sherbiny e col. ${ }^{6}$ salientaram que o resultado superior obtido na uretroplastia com mucosa bucal em retalho no cão se deve, sobretudo à preservação do tecido esponjoso e do urotélio dorsal os quais, segundo os autores, serviriam como um bloqueio da contração circunferencial do enxerto alem de promoverem a sua estabilidade, mantendo o seu alinhamento.

A mucosa bucal é um tecido elástico, resistente e facilmente obtido, embora Chen $e$ col. ${ }^{11}$ em decorrência das manobras para sua obtenção, o tempo cirúrgico pode ser aumentado em até uma hora caso não haja simultaneidade entre as etapas cirúrgicas. Além disso, este material apresenta uma grande densidade de capilares com uma fina lâmina própria, favorecendo a sua embebição e neovascularização ${ }^{14,15} \mathrm{O}$ sucesso dos implantes de mucosa bucal decorre ainda de sua grande limitação às complicações infecciosas uma vez que a cavidade oral está constantemente sujeita a traumas e a microrganismos patogênicos ${ }^{15,16}$.

Monfort $e$ col. ${ }^{16}$ apontaram as condições necessárias para o sucesso das uretroplastias por implantes livres de mucosa bucal. Entre estas pode-se citar a boa vascularização do leito recptor; uma rápida embebição do enxerto (primeiras 48 horas); ausência de retardo na revascularização (72 horas) e imobilização do mesmo.

A substituição por mucosa bucal, experimentalmente conduzida em cadelas, por Iizuka $e$ col. ${ }^{5}$ demonstrou que histológicamente ocorreu reparação do músculo estriado da uretra com mínima fibrose. O epitélio escamoso sobreviveu na luz da uretra dos animais sacrificados três a quatro semanas após a implantação e a parede uretral tornou-se totalmente atapetada por este epitélio nos animais sacrificados além deste período. Nas uretras nas quais 
ocorreu estenose, constatou-se espessamento da submucosa com leve infiltrado inflamatório nos sítios estenóticos. Barbagli e col. ${ }^{17}$ salientaram que existe uma tendência à deterioração do enxerto de mucosa bucal, especialmente dos tubulizados, e em função desta particularidade os acompanhamentos após uretroplastias no homem deveriam ser conduzidos por no mínimo cinco anos.

A execução deste estudo objetivou verificar se fragmentos de mucosa bucal poderiam ser utilizados para uretroplastia de substituição após ressecção uretral experimental no cão.

\section{Métodos}

Todos os procedimentos deste trabalho obedeceram às recomendações do COBEA (Colégio Brasileiro de Experimentação Animal) e para tanto foram utilizados 20 cães adultos, sem raça definida, com peso variando entre 10 a $15 \mathrm{Kg}$ e sem alterações clínicas, conforme confirmado por exames laboratoriais pré-operatórios. Os animais foram pré anestesiados com Clorpromazina ( $1 \mathrm{mg} / \mathrm{Kg})$ e a indução anestésica foi realizada por meio da administração de Tiopental Sódico na dose de $15 \mathrm{mg} / \mathrm{Kg}$. A manutenção anestésica foi feita em circuito fechado com Halotano.

Uma vez anestesiados os animais tiveram suas uretras cateterizadas com sonda descartável siliconizada. A uretra dos animais foi exposta por meio de incisão mediana entre a terminação do osso peniano e a base do escroto (Figura 1) e cerca de dois centímetros do seu comprimento foi extirpado.

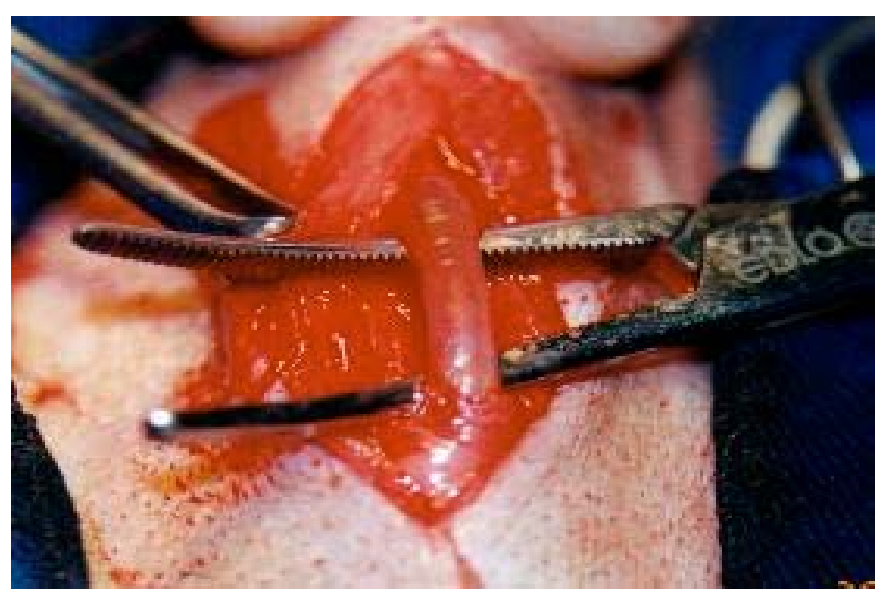

FIGURA 1 - Uretra peniana isolada dos tecidos periuretrais. Nota-se o rebatimento lateral do músculo retrator do pênis.

Fragmentos de mucosa provenientes do lábio superior foram meticulosamente liberados do tecido submucoso. A síntese da ferida bucal foi feita com sutura contínua simples (fio náilon 3-0). O fragmento de mucosa foi envolvido sobre a sonda uretral com a face mucosa voltada para esta (Figura 2), e suturado por meio de sutura contínua simples (fio categute cromado 4-0), formando um tubo que em seguida foi anastomosado em padrão término-terminal aos côtos remanescentes da uretra com pontos separados simples utilizando o mesmo fio da sutura precedente (Figura 3). 


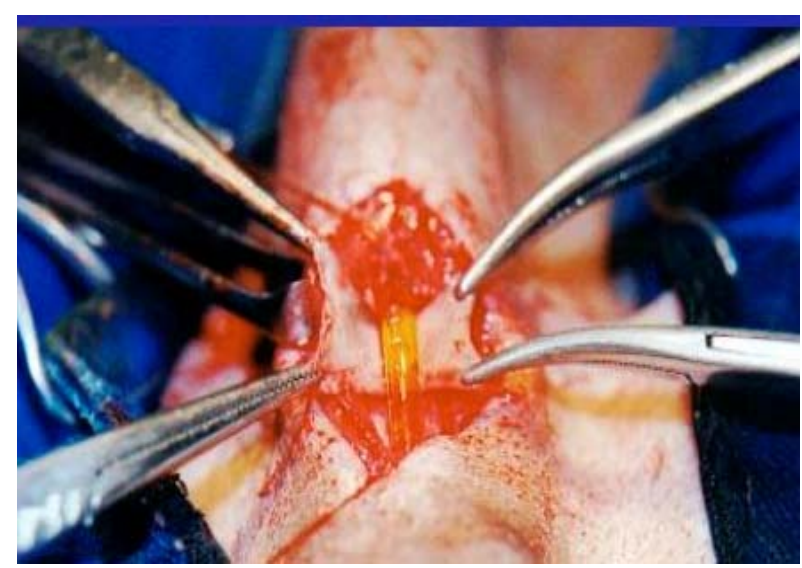

FIGURA 2 - Fragmento de mucosa bucal envolvendo sonda uretral. Observa-se a face mucosa voltada para a sonda.

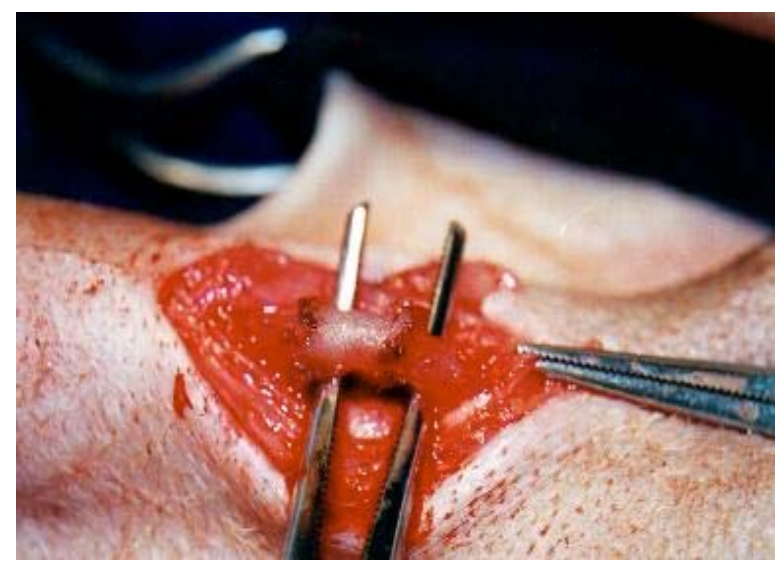

FIGURA 3 - Fragmento tubular de mucosa bucal anastomosado aos cotos uretrais.

Os tecidos peri-uretrais foram suturados com fio categute cromado 3-0 e a pele fio de náilon 3-0. A sonda uretral foi cortada rente à glande e fixada ao meato uretral por meio de dois pontos simples separados com fio de náilon 3-0.

O protocolo medicamentoso adotado no pós-operatório consistiu da administração de Enrofloxacina 2,5\% (5mg/Kg/IM), durante oito dias, Flunixin meglumine (1mg/Kg/IM) durante cinco dias. Aos 15 dias do pós-operatório procedeu-se à primeira avaliação radiográfica por meio de uretrografia contrastada retrógrada com contraste positivo iodado, diatrizoato de meglumina e de sódio.

Diariamente avaliou-se a presença ou ausência de fístula e o jato urinário e aos 60 dias de observação os animais foram submetidos à outra uretrografia. Após este procedimento, ainda sob anestesia geral barbitúrica, foram sacrificados por meio de injeção venosa de cloreto de potássio Foram então necropsiados, procedendo-se ao exame macroscópico do sistema urinário e a colheita de material para análise histopatológica.

\section{Resultados}

Dos 20 cães operados, oito $(40 \%)$ apresentaram edema escrotal, de moderado a importante, em geral, no $2^{\circ}$ dia pós-operatório. Tal alteração persistiu, em média cinco dias. Deiscência da sutura ocorreu em seis cães (30\%) e a cicatrização nestes casos foi por segunda intenção. Oito animais (40\%) apresentaram sangramento na ferida cirúrgica, com duração média de três dias. Fístulas uretro-cutâneas de persistência média de sete dias ocorreram em 11 cães (55\%). Estes dados estão representados na Tabela 1. Todas as fístulas cicatrizaram espontaneamente. Os animais alimentaram-se de ração comercial no dia seguinte e não forma observadas alterações morfológicas na face. Pode-se observar discreta presença de urina na interface sonda/parede uretral em todos os animais e as sondas uretrais foram perdidas em média no $2^{\circ}$ dia.

TABELA 1 - Principais alterações observadas durante avaliação pós-operatória de cães submetidos à uretroplastia de substituição com mucosa bucal. 


\begin{tabular}{|l|c|c|}
\hline Alteração apresentada & $\begin{array}{c}\text { Número de animais- } \\
(\%)\end{array}$ & $\begin{array}{c}\text { Persistência média da alteração } \\
\text { em dias }\end{array}$ \\
\hline Edema escrotal & $08(40)$ & 02 \\
\hline Deiscência de sutura & $06(30)$ & - \\
\hline Sangramento PO & $08(40)$ & 03 \\
\hline Fístula uretro-cutânea & $11(55)$ & 07 \\
\hline
\end{tabular}

Entre os animais operados, $14(70 \%)$ apresentaram jato urinário normal e seis $(30 \%)$ evidenciaram estrangúria sugestiva de estenose (Figura 4), dados estes confirmados radiográficamete aos 60 dias pós-operatório (Figura 5).

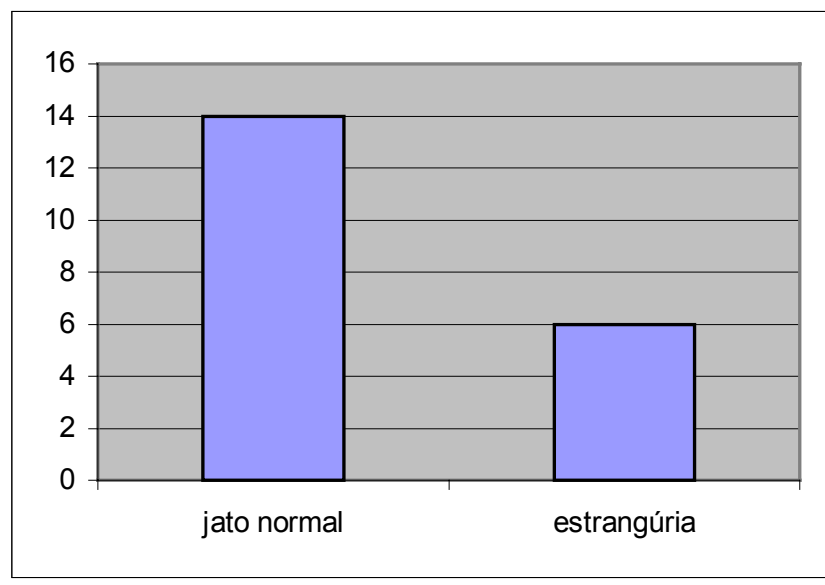

FIGURA 4 - Representação gráfica do número de cães que apresentaram estrangúria e dos que apresentaram iato normal de urina aos 60 dias nós-oneratório.

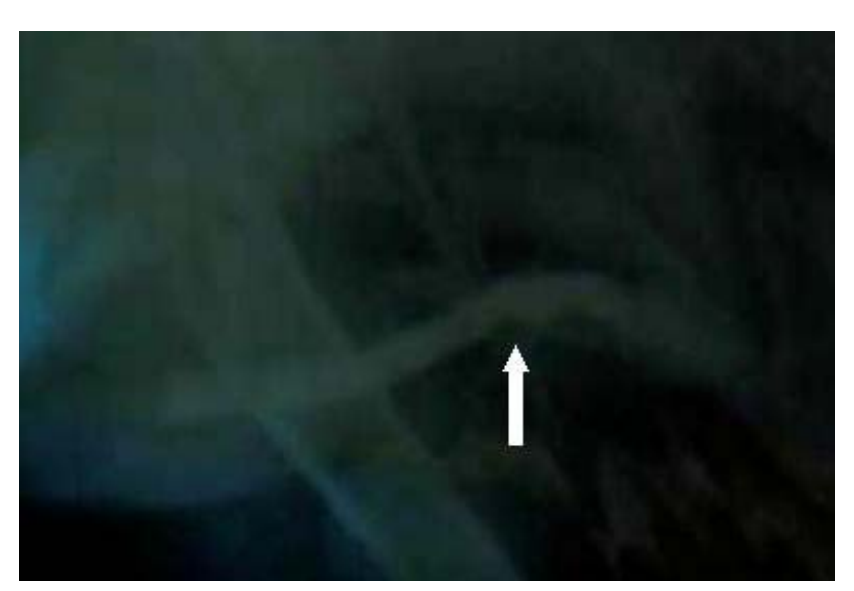

FIGURA 5 - Imagem radiográfica de uretra submetida a uretroplastia com mucosa bucal aos 60 dias de observação.

O aspecto macroscópico observado aos 60 dias evidenciou em todos os animais a completa integração do implante ao leito receptor e aos tecidos uretrais. A análise histológica das amostras coletadas aos 60 dias do pósoperatório mostrou presença de revestimento epitelial nos fragmentos do canal uretral. Hiperemia nos sítios implantares (Figura 6) e importante cistite foram observadas nas amostras avaliadas. 


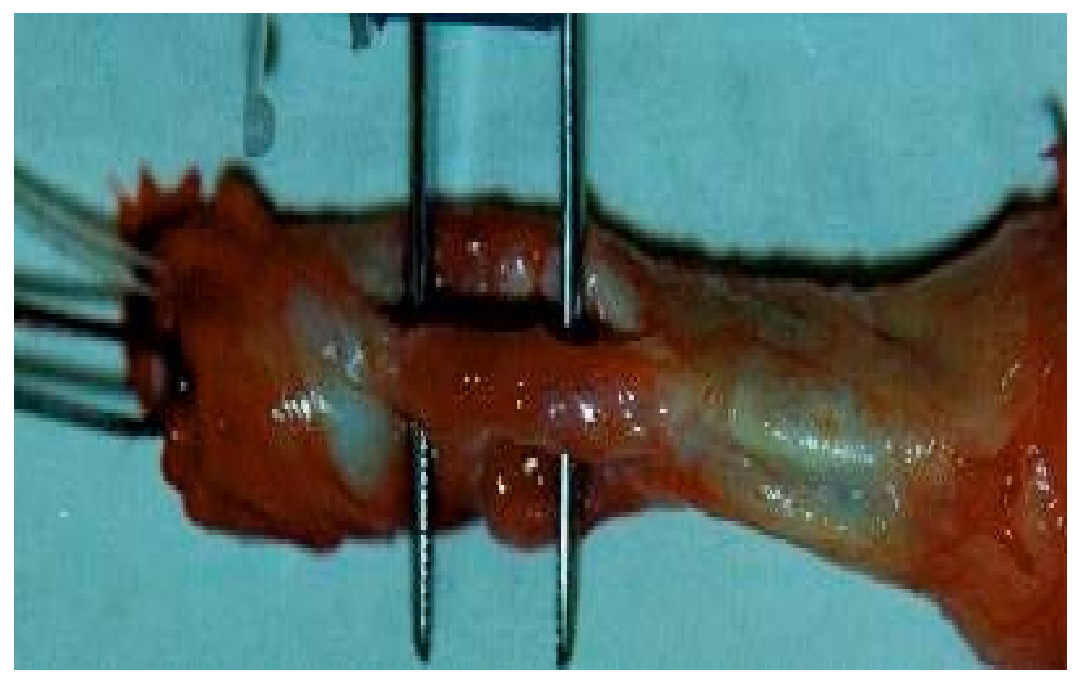

FIGURA 6 - Fragmento de mucosa bucal implantado na uretra aos 60 dias de observação. Nota-se a hiperemia no implante.

\section{Discussão}

A escolha da mucosa bucal para uretroplastia de substituição se deve às diversas vantagens da sua aplicação, reportadas no homem ${ }^{4}$. Tal opção para o cão fundamentou-se nos relatos de El-Sherbiny e col. ${ }^{6}$ que obtiveram resultados superiores deste material quando o compararam à pele e a mucosa vesical.

Estenoses e fístulas da anastomose de implantes de mucosa bucal, são as complicações mais freqüentemente encontradas após reconstrução uretral ${ }^{4,6}$. No presente trabalho foi encontrado um índice de $30 \%$ de estenoses, e tal resultado não pode ser comparado aquele citado pelos autores mencionados já que os mesmos se reportaram ao homem no qual as medidas preventivas pós-operatórias incluem desde a derivação supra-púbica da urina por duas semanas até bandagens compressivas na região do períneo durante cinco dias ${ }^{14}$.

Entre outras alternativas citadas para prevenção de estenoses pós-uretroplastias com mucosa bucal no homem, Pansadoro $e$ col. ${ }^{14}$ salientaram que a correta aposição da mucosa bucal ao corpo cavernoso promove uma abertura da luz uretral mesmo que o implante não sobreviva. Além dos fatores acima relacionados para prevenção de estenose, os autores acrescentaram o adequado suprimento sanguíneo e a efetiva embebição do enxerto como elementos fundamentais na enxertia uretral. Com o mesmo propósito, Kröpfl e col. ${ }^{4}$ sugeriram a formação de terminações biseladas nos implantes. Os índices de estenose reportados neste trabalho são seguramente superiores aos referidos na literatura. As causas para o desenvolvimento de estenoses no presente estudo permanecem incertas embora Iizuka $e$ col. ${ }^{5}$ tenham atribuído o processo inflamatório observado nas amostras de uretra de cadelas submetidas a implante de mucosa bucal, à exposição do tecido conectivo à urina extravasada da região da anastomose, o que provavelmente também possa estar relacionado às estenoses observadas, já que houve passagem de urina, ainda que discretamente na interface sonda/parede uretral. Já para Monfort e col. ${ }^{16}$ a remoção criteriosa do tecido submucoso é importante para prevenção de estenoses. Tal 
critério foi rigidamente obedecido no nosso trabalho quando procurou-se deixar a membrana a ser implantada o mais fina possível.

Considerando a formação de fístulas, Greenwell $e$ col. ${ }^{13}$ salientam que a falha na interposição das camadas teciduais ou mesmo a necrose isquêmica da pele ou dos demais tecidos sobrepostos ao implante poderiam contribuir para tal complicação. El-Sherbiny e col. ${ }^{6}$ relataram o desenvolvimento de fístula em um animal, num grupo de quatro submetidos a uretroplatia tubular de mucosa bucal na uretra perineal e neste caso puderam observar que histológicamente ocorreu perda do tecido implantado. O índice 55\% de fístulas em nosso trabalho são superiores aos observados por outros autores embora estes tenham se referido a espécies e sítios implantares diferentes. Relatos sugerem que implantes uretrais em retalho apresentam resultados melhores do que os tubulares no tocante à gênese das fístulas ${ }^{6,17}$.

A análise histológica das amostras coletadas aos 60 dias de observação mostrou presença de revestimento epitelial nos fragmentos do canal uretral, evidenciando infiltrado inflamatório de neutrófilos, linfócitos piócitos e histiócitos. Estes resultados sugerem inflamação, o que também foi observado por Iizuka e col. ${ }^{5}$. em uma cadela submetida a uretroplastia experimental com mucosa bucal. Os autores atribuíram tal achado à presença de urina sobre as anastomoses, embora todos os animais por eles utilizados tenham sido submetidos à derivação suprapúbica de urina. Em nosso estudo semelhante processo ocorreu em todos os cães, o que pode provavelmente ser atribuído às mesmas razões mencionadas pelos autores acima. Na tentativa de minimizar a irritação da urina sobre as anastomoses, no presente estudo foi adotada a sutura da sonda uretral na glande, o que promoveu a sua imobilização, mas não a presença da urina sobre a anastomose. Este método foi sugerido por El-Sherbiny e col. ${ }^{6}$ e pudemos observar que embora efetivamente ocorra a permanência da sonda, existiu tendência à perda já no $2^{\circ}$ dia do pós-operatório. A identificação histológica das junções uretra-mucosa bucal verificada por estes autores nas uretras de cães aos três meses do pós-operatório mostrou neovascularização, agregação de células inflamatórias e reação fibroblástica de forma semelhante a encontrada em nosso estudo.

\section{Conclusão}

A mucosa bucal autóloga pode ser utilizada para reconstrução uretral experimental no cão, embora possa ocorrer a formação de estenoses.

\section{Referências}

1. Dessanti A, Porcu A, Scanu AM, Dettori G, Caccia G. Labial mucosa and combined labial/bladder mucosa free graft for uretral reconstrution. J Pediatr Surg 1995; 11: $1554-6$. 
2. Morey AF, McAninch JW, Technique of harvesting buccal mucosa for urethral reconstruction. J Urol 1996; 155:1696-7.

3. Macedo Jr A, Fichtner J, Fisch M, Srougi M, Hohenfellner R. Novos conceitos em hipospádia: utilização de mucosa bucal para reconstrução da uretra. Rev Paul Ped 1997; 15: 14 - 6.

4. Kröpfl D, Tucak A, Prlic D, Verweyen A. Using buccal mucosa for urethral reconstruction in primary and reoperative surgery. Ped Urol 1998; 34: 216-20.

5. Iizuka K, Muraishi O, Maejima T, Kitami YXY, Watanabe K, Ogawa A. Total replacement of urethral mucosa with oral mucosa in dogs. J Urol 1996; 156: 498 -501.

6. El-Sherbiny MT, Abol-Enein MS, Dawaba MS, Ghoneim MA. Treatment of urethral defects: skin, buccal or bladder mucosa, tube or patch? An experimental study in dogs. J Urol 2002; 167: 2225 - 28.

7. Bojrab MJ. Infecções bacterianas do trato urinário canino e felino: causa, cura e controle. In Bojrab MJ. Mecanismo da moléstia na cirurgia dos pequenos animais. 2 ed. São Paulo: Manole; 2001. p. 502 - 42.

8. Andrich DE, Leach CJ, Mundy AR. The Barbagli procedure gives the best results for patch urethroplasty of the bulbar urethra. Brit J Urol 2001; 88: 385-9.

9. Da Silva EA, Telo Z. Substituición de Ia uretra com material sintético. Acta Urol Esp 2000; $24: 235$ - 42.

10. Yavuzer R, Baran C, Latifoglu O, Cenetoglu S, Baran NK. Vascularized double-sided preputial island flap with W flap glanuloplasty for hypospadias repair. Plast Reconst Surg 1998; 101: 751-5.

11. Chen F, Yoo JJ, Atala A. Acellular collagem matrix as a possible "off the shelf" biomaterial for urethral repair. Urology 1999; 54: $406-10$.

12. Brock JW. Autologous buccal mucosal graft for urethral reconstruction. Urology 1994; 44: 753-5.

13. Greenwell TJ, Venn SN, Mundy AR. Changing practice in anteiror urethroplasty. 1999 Br J Urol; 83: 631-5.

14. Pansadoro V, Emiliozzi P, Gaffi M, Scarpone P. Buccal mucosa urethroplasty for the treatment of bulbar urethral strictures. J Urol 1999; 161: 1501-3.

15. Eppley BL, Eating M, Rink RA. buccal mucosal harvesting technique for urethral reconstruction. J Urol 1997; 157: $1268-70$.

16. Monfort G, Di Benedetto V, Meyrat BJ. Sténoses urétrales chez l'enfant: traitment par urétroplasthie avec greffon du muqueuse vésicale ou buccale. Ann. Fano 1993; 27: 237-42.

17. Barbagli G, Palminteri E, Rizzo M. Dorsal onlay graft uretroplaty using penile skin or buccal mucosa in adult bulbourethral strictures. J Urol 1998; 160: 1307-9. 
Paulo NM, Rôlla ABS, Porto SM, Silva LS, Brito GA, Freitas JS. Substitutive urethroplasty with autologous tubular segments of bucal mucosa in dogs. Acta Cir Bras [serial online] 2003 JulAug;18(4). Available from URL: http://www.scielo.br/acb.

\begin{abstract}
Purpose: Evaluate experimental urethral defects reconstruction in dogs through implantation of tubular oral autologous mucosa fragments. Methods: About $2 \mathrm{~cm}$ of penile urethra was resected. The induced defect was repaired through anastomosis of tubular oral autologous mucosa fragment extracted from the lower lip. Results: 14 (70\%) of the operated dogs showed normal urinary flow and $6(30 \%)$ revealed stenosis which was revealed by radiological examination carried out at 60 days post-operative. Necropsy findings showed the integrity of the implants to the urethral sulcus, and histological findings confirmed that the implanted fragments were covered by the urethral epithelium and inflammatory infiltration of neutrophils, lymphocytes and macrophages was present. Conclusion: Implantation of tubular oral autologous mucosa fragments is adequate to reconstruct urethral iatrogenic defects in dogs, although it may result in post-operative stenosis.
\end{abstract}

KEY WORDS - Urethra. Transplantation, autologous. Mouth mucosa.

Correspondência:

Conflito de interesse: nenhum Fonte de financiamento: $\mathrm{CNPq}$

Dra Neusa Margarida Paulo

Disciplina de Cirurgia Veterinária / Depto. Medicina Veterinária/ Hospital Veterinário

Universidade Federal de Goiás / Campus 2 - Samambaia

74001-970 Goiânia - GO

Tel: (62)521-1587

nmp@,vet.ufg.br 